\title{
A narrative review of cost-effectiveness analysis of people living with HIV treated with HAART: from interventions to outcomes
}

This article was published in the following Dove Press journal:

ClinicoEconomics and Outcomes Research

II August 2015

Number of times this article has been viewed

\author{
Wah Fung Tse' \\ Weimin Yang ${ }^{2}$ \\ Wenlong Huang 1,3 \\ 'School of International \\ Pharmaceutical Business, China \\ Pharmaceutical University, ${ }^{2}$ Editorial \\ Department of Journal of Nanjing \\ University of Traditional Chinese \\ Medicine, Nanjing University of \\ Chinese Medicine, ${ }^{3}$ Center of Drug \\ Discovery, State Key Laboratory \\ of Natural Medicines, China \\ Pharmaceutical University, Nanjing, \\ People's Republic of China
}

Background: Since its introduction in 1996, highly active antiretroviral therapy (HAART), which involves the combination of antiretroviral drugs, has resulted in significant improvements in the morbidity, mortality, and life expectancy of HIV-infected patients. Numerous studies of the cost-effectiveness of HAART from different perspectives in HIV have been reported.

Aim: To investigate the economic outcomes and relevance of HAART for people living with HIV.

Materials and methods: A narrative literature review was conducted on 22 peer-reviewed full economic evaluations of people living with HIV treated with different HAART regimens and published in English between January 2005 and December 2014. Information regarding study details, such as interventions, outcomes, and modeling methods, was extracted. The high heterogeneity of the included studies rendered a meta-analysis inappropriate; therefore, we conducted a comparative analysis of studies grouped according to the similarity of the different intervention types and outcomes.

Results: Most of the economic evaluations of HAART focused on comparisons between the specific HAART regimens and others from the following perspectives: injecting drug users versus noninjecting drug users, HIV-infected adults without AIDS versus those with AIDS, regimens based on developed world guidelines versus those based on developing world guidelines, self-administered HAART versus directly observed HAART, and "ideal" versus "typical" regimens.

Conclusion: In general, HAART is more cost-effective than other therapeutic regimens adopted so far. Further investigations, especially head-to-head comparisons of "ideal" and "typical" trials of different regimen combinations, are required to identify the optimal HAART regimens.

Keywords: narrative review, cost-effectiveness, HAART

\section{Introduction}

AIDS, which is caused by HIV, is recognized as one of the world's greatest health problems. HIV is transmitted in human body fluids by three major routes: 1) sexual intercourse; 2) direct injection with HIV-contaminated drugs, needles, syringes, blood, or blood products; and 3) from HIV-infected mother to fetus in utero, through intrapartum inoculation from mother to infant or during breastfeeding. CD4 ${ }^{+} \mathrm{T}$-cell count ranges are a major indicator of the disease stage. In the peripheral blood of a normal healthy individual, the level of CD4 ${ }^{+}$T-cells is between 800 and $1,200 / \mathrm{mm}^{3}$, and once this number reaches 200 or below in an HIV-infected patient, the person is classified
Correspondence: Wenlong Huang School of International Pharmaceutical Business, China Pharmaceutical University, 639 Longmian Avenue, Jiangning, Nanjing, Jiangsu 211198 , People's Republic of China Tel/fax +86 $258327 \quad$ I 480

Email ydhuangwenlong@I26.com 
as having AIDS. The data for the prevalence and incidence of HIV presented by the Joint United Nations Programme on HIV/AIDS (UNAIDS) and World Health Organization (WHO) showed that 33.3 million people around the world were HIV-infected in 2009, while in 2013 the number had reached 35 million. ${ }^{1}$

Since highly active antiretroviral therapy (HAART) became available in the mid-1990s, clinical trial results have demonstrated its effectiveness and the life expectancy of patients has increased significantly. ${ }^{2,3}$ At the same time, the introduction of antiretroviral therapy has dramatically reduced mortality for people with HIV infection. HAART usually comprises a cocktail of multiple anti-HIV drugs, including reverse-transcriptase inhibitors, protease inhibitors (PIs), fusion inhibitors, coreceptor antagonists, and integrase inhibitors. It has been suggested that increasing coverage with HAART among people infected with HIV with medical indication for HAART may help to prevent new infections. ${ }^{4}$ In the published literature, most studies have focused on specific comparisons of HAART from different perspectives. In this review, we focus on the effects of HAART to identify the optimal regimen to obtain more economically viable outcomes.

\section{Materials and methods Study design}

We searched major databases (Embase, Medline, and Web of Science) for reports published between 2005 and 2014.
We constructed two search strings to identify as many relevant studies as possible: ((HAART[Title Abstract]) AND HIV[Title Abstract]) AND cost[Title Abstract], or ((HAART[Title Abstract]) AND HIV[Title Abstract]) AND economic[Title Abstract]. References of retrieved publications and relevant overview publications were checked to identify additional studies. The review considered both random and nonrandom controlled studies. The literaturesearch and selection process is presented in Figure 1.

\section{Data extraction}

Two authors carried out the data extraction independently using a set format. Information from the 22 selected publications are provided in Tables 1 and 2, including author, region, perspective, study population, modeling, timescale, discount, interventions, and outcome and sensitivity analyses. Outcome measures were divided into several categories: qualityadjusted life-years (QALYs)/disability-adjusted life-years (DALYs), life-years gained, net benefit, and incremental cost-effectiveness ratio (ICER).

\section{Results}

The database search yielded 371 possible studies for the review. The number was reduced to 83 articles after removal of duplicates and an initial selection on the basis of titles. After screening of the titles, abstracts, and full text, 22 studies were included in this review.

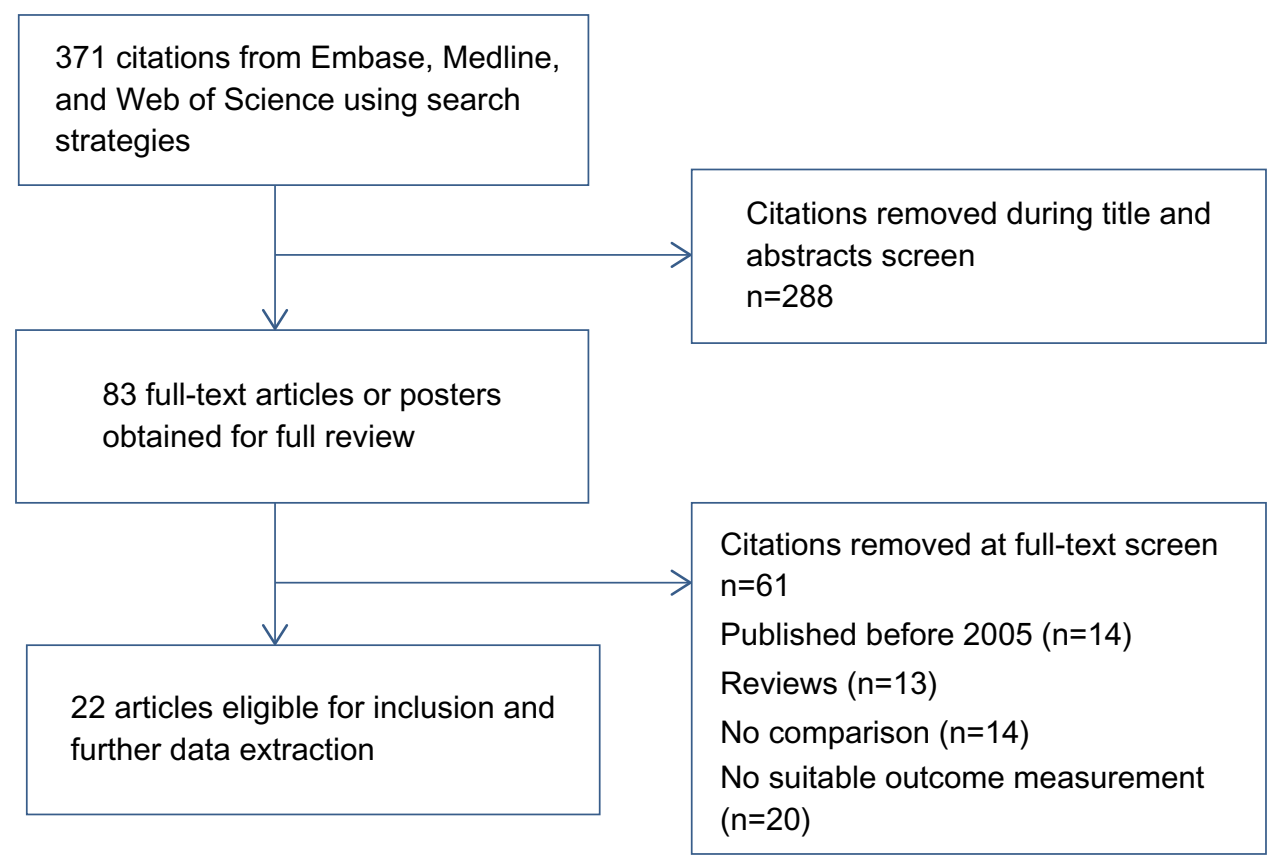

Figure I Summary of study-search and selection process. 
Table I Study characteristics

\begin{tabular}{|c|c|c|c|c|c|c|}
\hline Reference & Region & Perspective & Population & Modeling & Timescale & Discount \\
\hline Moeremans et $\mathrm{al}^{5}$ & $\begin{array}{l}\text { Belgium, Italy, } \\
\text { Sweden, UK }\end{array}$ & $\begin{array}{l}\text { Reimbursement } \\
\text { authorities }\end{array}$ & HIV-infected adults & Markov model & Lifetime & $\begin{array}{l}\text { Based on local } \\
\text { guidelines }\end{array}$ \\
\hline Long et $\mathrm{al}^{6}$ & St Petersburg, Russia & NA & IDUs and non-IDUs & $\begin{array}{l}\text { Dynamic HIV- } \\
\text { epidemic model }\end{array}$ & 20 years & $3 \%$ \\
\hline Vijayaraghavan et $\mathrm{al}^{7}$ & South Africa & NA & HIV-positive adults & Markov model & Lifetime & NA \\
\hline Hubben et $\mathrm{al}^{8}$ & The Netherlands & Dutch health care & HIV-infected patients & Markov model & Lifetime & $4 \%, 1.5 \%$ \\
\hline Johnston et $\mathrm{al}^{9}$ & $\begin{array}{l}\text { British Columbia, } \\
\text { Canada }\end{array}$ & Payers & Asymptomatic HIV patients & $\begin{array}{l}\text { Mathematical } \\
\text { model }\end{array}$ & 30 years & NA \\
\hline Binagwaho et al $^{10}$ & Rwanda & Health care payers & Pregnant women & NA & Lifetime & $3 \%$ \\
\hline Orlando et al" & Malawi & Private, public & Pregnant women & NA & NA & $15 \%$ \\
\hline Brogan et al ${ }^{12}$ & USA & Societal & HIV-infected adults & Markov model & Lifetime & $3 \%$ \\
\hline Simpson et $\mathrm{al}^{13}$ & USA & Payers & $\begin{array}{l}\text { Treatment-experienced } \\
\text { HIV Patients }\end{array}$ & Markov model & Lifetime & $3 \%$ \\
\hline Badri et al ${ }^{14}$ & South Africa & $\begin{array}{l}\text { Public healthcare } \\
\text { system }\end{array}$ & $\begin{array}{l}\text { HIV-infected adults without } \\
\text { AIDS and with AIDS }\end{array}$ & NA & NA & NA \\
\hline Marseille et $\mathrm{al}^{15}$ & Rural Uganda & Societal & HIV-infected patients & NA & 15 years & $3 \%$ \\
\hline Rizzardini et al ${ }^{16}$ & Italy & $\begin{array}{l}\text { Lombardy } \\
\text { Regional Health } \\
\text { Service }\end{array}$ & $\begin{array}{l}\text { Adult HIV subjects who } \\
\text { received HAART therapy } \\
\text { for the first time }\end{array}$ & Markov model & 2 years & None \\
\hline Colombo et $\mathrm{al}^{17}$ & Italy & $\begin{array}{l}\text { Italian National } \\
\text { Health Service }\end{array}$ & HIV-infected patients & Markov model & 10 years & $3.50 \%$ \\
\hline McCabe et al ${ }^{18}$ & NA & Societal & $\begin{array}{l}\text { HIV-infected pregnant } \\
\text { women }\end{array}$ & $\begin{array}{l}\text { Mathematical } \\
\text { model }\end{array}$ & Lifetime & $3 \%$ \\
\hline Munakata et al ${ }^{19}$ & NA & Societal & $\begin{array}{l}\text { HIV patients on an initial } \\
\text { regimen of HAART }\end{array}$ & Markov model & Lifetime & $3 \%$ \\
\hline Colombo et $\mathrm{al}^{20}$ & Italy & $\begin{array}{l}\text { Italian health care } \\
\text { system }\end{array}$ & HIV-infected patients & Markov model & 10 years & $3.50 \%$ \\
\hline Granich et $\mathrm{al}^{21}$ & South Africa & NA & HIV-infected patients & Epidemic model & 40 years & $3 \%$ \\
\hline Fang et $\mathrm{al}^{22}$ & Taiwan & $\begin{array}{l}\text { National health } \\
\text { insurance }\end{array}$ & $\begin{array}{l}\text { HIV-positive patients and } \\
\text { AIDS }\end{array}$ & NA & NA & NA \\
\hline Ono et $\mathrm{al}^{23}$ & Thailand & NA & HIV-infected patients & Markov model & NA & $3 \%$ \\
\hline Badri et $\mathrm{al}^{24}$ & Sub-Saharan Africa & Public health & HIV-infected patients & Markov model & Lifetime & $8 \%$ \\
\hline Mauskopf et al ${ }^{25}$ & NA & NA & HIV-infected patients & Markov model & 25 years & $3 \%$ \\
\hline Mauskopf et al ${ }^{26}$ & USA & NA & $\begin{array}{l}\text { Treatment-experienced } \\
\text { patients }\end{array}$ & Markov model & 5 years, lifetime & $3 \%$ \\
\hline
\end{tabular}

Abbreviations: NA, not applicable; IDUs, injecting drug users; HAART, highly active antiretroviral therapy.

\section{Study characteristics}

The 22 studies included different regions (Table 1); most focused on the West, where HAART is widely used, and African countries, where HIV is a more severe problem. Most of the studies were conducted from societal ${ }^{12,15,18,19}$ and payer ${ }^{8-11,13,14,16,17,20,24}$ perspectives (Table 1), while some of them did not mention these aspects (Table 1). ${ }^{6,7,21,23,25,26}$ The majority of studies (18 of 22) focused on HIV-infected patients, while three focused on pregnant women and one on infected drug users.

\section{Timescale and discount}

For cost-effectiveness analyses of HAART, these studies were generally based on a lifetime perspective (ten of 22), while other studies considered timescales ranging from 2 to 40 years. What is apparent from all the analyses of specific HAART regimens presented in this review paper was that although the results were consistent with each other, they varied depending on the timescale under consideration. Most of the individual studies applied a discount of 3\%, $6,10,12,13,15,18,19,21,23,25,26$ while discounts of $1.5 \%,{ }^{8} 3.5 \%,{ }^{17,20} 4 \%,{ }^{8} 8 \%,{ }^{24}$ and $15 \%{ }^{11}$ were also applied in some studies.

\section{Interventions}

Because of the diversity of the interventions (Table 2), the high heterogeneity of the data rendered a meta-analysis inappropriate; therefore, we conducted a comparative analysis of studies grouped according to the similarity of the different intervention types and outcomes.

One group comprised all the studies that contained the specific regimen of HAART (eight)..$^{5,8,12,13,16,17,20,26}$ The variety of combination-treatment regimens represented in this group 


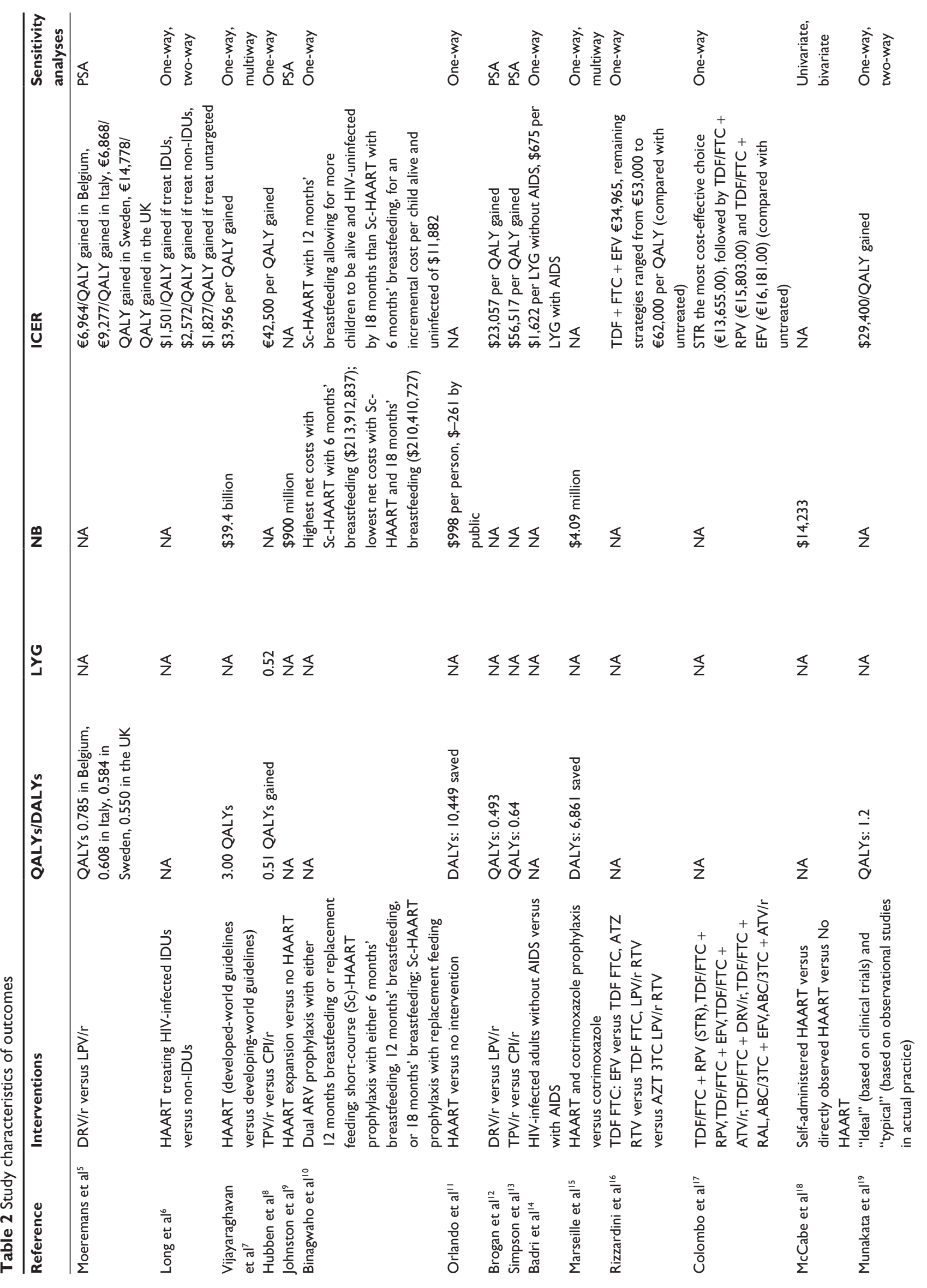




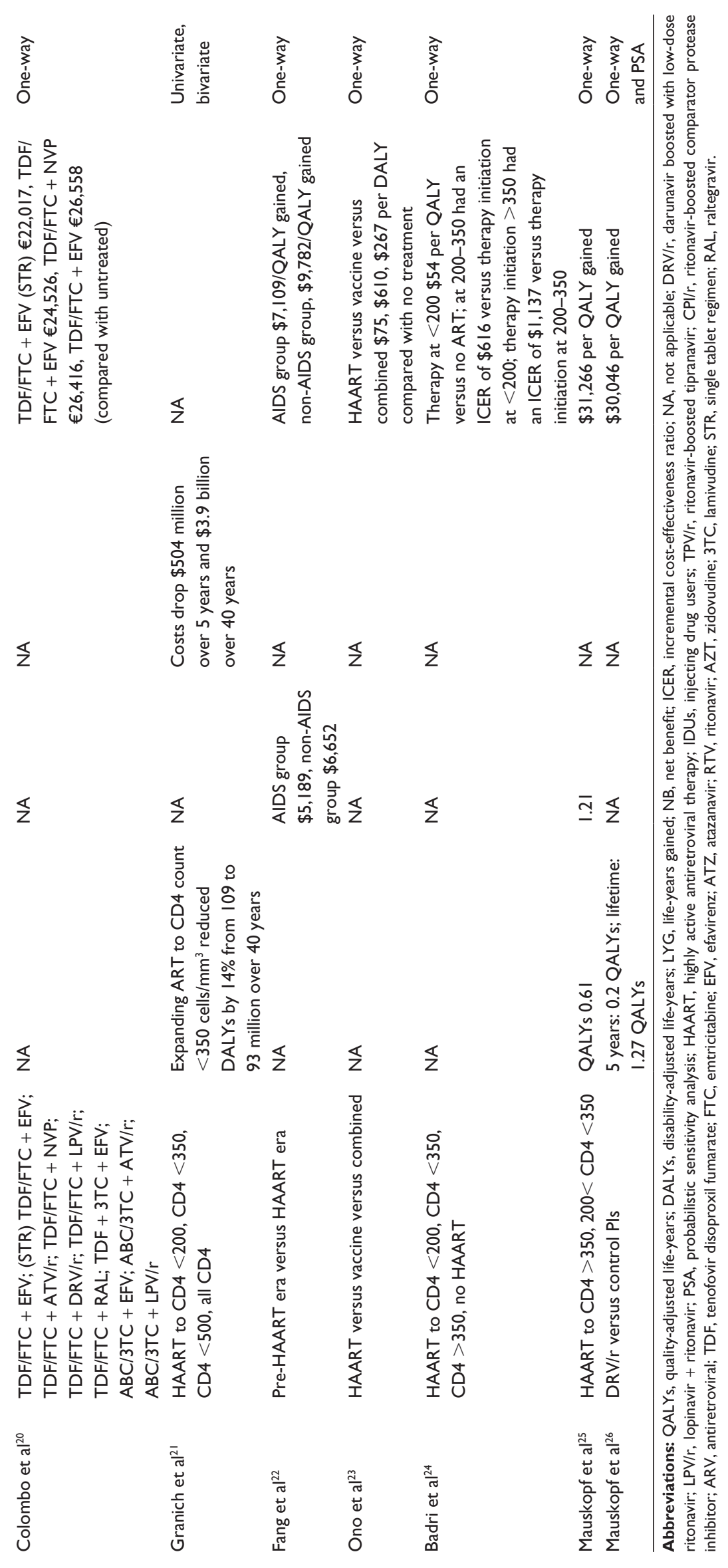


demonstrate the importance of identifying and standardizing the optimal regimen in further pharmacoeconomic evaluations.

The second group comprised studies that compared HAART with no intervention (three $)^{9,11,22}$ with the aim of performing an economic evaluation of these approaches. Outcomes estimated were cost for DALYs saved and incremental net benefit. The results supported the cost-effectiveness of HAART.

The third group comprised the studies that aimed to determine the optimal initiation time for HAART from the perspective of $\mathrm{CD}^{+} \mathrm{T}$-cell count ranges (three). ${ }^{21,24,25}$ This population is an essential component of the immune system, and the numbers of these cells are important in confirming the effect of AIDS treatment. Furthermore, identifying the optimal time to treat with HAART could reduce the cost of therapy and reduce the DALYs.

The fourth group comprised studies that compared HAART applied among different groups of people (three), ${ }^{6,10,14}$ such as injecting drug users (IDUs) versus nonIDUs, HIV-infected adults without AIDS versus those with AIDS, and different alternatives of breastfeeding duration for HIV-positive pregnant women.

The fifth group comprised studies that compared the effects of different types of HAART (three), ${ }^{7,18,19}$ administered on the basis of developed-world guidelines versus developing-world guidelines, self-administered HAART versus directly observed HAART versus no HAART, and "ideal" treatment (based on clinical trials) versus "typical" treatment (based on observational studies in actual practice).

The last group comprised studies that compared HAART with other types of treatment (two), ${ }^{15,23}$ such as HAART + cotrimoxazole prophylaxis versus cotrimoxazole, and HAART versus vaccine versus HAART + vaccine.

\section{Study outcomes}

Outcomes of the 22 selected publications are provided in Table 2. The effectiveness of therapeutic regimens for treating HIV infection was evaluated using several outcome measures. Most of the studies took life-years gained (LYG), ${ }^{8,22,25}$

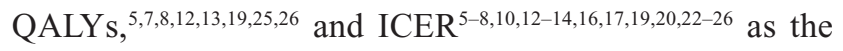
main outcomes, which are the most important measurement indicators in an economic evaluation, especially ICER. Some other studies used DALYs ${ }^{11,15,21}$ and net benefit ${ }^{7,9,10,11,15,18,21}$ as the primary indicators to measure the averted loss of life-years and cost by HAART.

Studies were categorized into the following types based on the outcomes: 1) cost-effectiveness/cost-utility analyses,
2) cost-benefit analyses, and 3) studies focusing on life-year loss averted due to HAART. We identified eight studies comparing the cost-effectiveness analyses of the specific HAART regimens; two compared darunavir + low-dose ritonavir $(\mathrm{DRV} / \mathrm{r})$ with lopinavir + ritonavir. ${ }^{5,12}$ Comparable studies were performed in five different countries, with incremental QALYs gained of 0.785 in Belgium, 0.608 in Italy, 0.584 in Sweden, 0.550 in the UK, and 0.493 in the US, as well as ICERs of $€ 6,964 /$ QALY gained in Belgium, €9,277/QALY gained in Italy, €6,868/QALY gained in Sweden, €14,778/ QALY gained in the UK, and \$23,057/QALY gained in the US. Two of them compared ritonavir-boosted tipranavir to an investigator-selected ritonavir-boosted comparator PI, ${ }^{8,13}$ with incremental QALYs gained ranging from 0.51 to 0.64 and ICERs ranging from $€ 42,500$ to $\$ 56,517$. One of the reported life year gained was 0.52 .

Three studies compared four to seven types of therapeutic combinations. Rizzardini et $\mathrm{al}^{16}$ indicated that compared with untreated controls, the ICER of tenofovir disoproxil fumarate (TDF) + emtricitabine (FTC) + efavirenz (EFV) was $€ 34,965$, and remaining strategies ranged from $€ 53,000$ to $€ 62,000$ per QALY. Colombo et $\mathrm{al}^{20}$ showed that compared with untreated controls, the ICER of TDF/FTC + EFV (single-tablet regimen) was $€ 22,017$, while that of TDF/FTC + EFV was $€ 24,526$, TDF/FTC + NVP was $€ 26,416$, and TDF/FTC + EFV was $€ 26,558$. Colombo et $\mathrm{l}^{17}$ also reported similar research demonstrating that compared with untreated controls, the ICER of the single-tablet regimen was $€ 13,655$, followed by TDF/ $\mathrm{FTC}+\mathrm{RPV}$ and TDF/FTC + EFV with ICERs of $€ 15,803.00$ and $€ 16,181.00$, respectively. Another study compared DRV/r to other control PIs. ${ }^{26}$ The incremental QALYs gained were 0.2 in a 5-year scenario and 1.27 in a lifetime scenario. The ICER was \$30,046 per QALY gained.

We also identified three cost-effectiveness analyses of comparisons between HAART and no interventions. Johnston et $\mathrm{al}^{9}$ showed that the HAART-expansion scenario was associated with a net benefit of $\$ 900$ million over 30 years. They also reported a significant gap wherein from a private perspective, the cost for HIV infection averted was $\$ 998$ per person and cost per DALY saved was $\$ 35.36$; from a public perspective, the results were $\$-261$ and $\$-16.55$ (lower cost than that of therapy for an $\mathrm{HIV}^{+}$child), respectively, for pregnant women. They divided the population into two groups. In the AIDS group, the cost was \$5,189 per LYG and $\$ 7,109$ per QALY gained, while in the non-AIDS group, it was $\$ 6,652$ per LYG and \$9,782 per QALY gained.

Three of the studies compared the different scenarios in terms of $\mathrm{CD}^{+} \mathrm{T}$-cell count ranges. Granich et $\mathrm{al}^{21}$ indicated 
that compared to CD4 counts $<200$ cells $/ \mathrm{mm}^{3}$, expanding ART to CD 4 counts $<350$ cells $/ \mathrm{mm}^{3}$ reduced DALYs by $14 \%$, from 109 to 93 million over 40 years. Costs dropped by $\$ 504$ million over 5 years and by $\$ 3.9$ billion over 40 years, with breakeven by 2013. Expanding ART to all CD4 levels reduced HIV infections by 3.3 million ( $45 \%$ ) and treatment costs by $\$ 10$ billion over 40 years. Badri et al ${ }^{14}$ showed that therapy started at CD4 $<200$ cells $/ \mathrm{mm}^{3}$ displayed an ICER of \$54 per QALY versus no ART. Treatment initiated at CD4 of 200-350 cells $/ \mathrm{mm}^{3}$ exhibited an ICER of $\$ 616$, while therapy started at CD4 counts $<200$ cells $/ \mathrm{mm}^{3}$ and CD4 $>350$ cells $/ \mathrm{mm}^{3}$ showed an ICER of $\$ 1,137$. Mauskopf et $\mathrm{al}^{25}$ conducted a comprehensive study showing that compared to the treatment group initiated at CD4 counts of 200-350 cells $/ \mathrm{mm}^{3}$, starting HAART at CD4 counts $>350$ cells $/ \mathrm{mm}^{3}$ increased years of life by 1.21 , discounted QALYs by 0.61 , and showed an ICER of $\$ 31,266$ per QALY. It was determined that economic implications were associated with the clinical efficacy of alternative treatments, because treatment of HIV-infected individuals in the later stages is the most costly. Early therapy was more cost-effective when the impact of HAART on well-being was smaller.

Three analyses focused on the application of HAART among different populations. Long et $\mathrm{al}^{6}$ compared the cost-effectiveness of HAART between IDUs and non-IDUs. Compared with no intervention, \$1,501 per QALY gained was required to treat an IDU, while $\$ 2,572$ per QALY gained was necessary to treat a non-IDU and \$1,827 per QALY gained if treatment-eligible IDUs and non-IDUs received HAART. Binagwaho et $\mathrm{al}^{10}$ modeled the cost-effectiveness of six HAART regimens classified by breastfeeding duration for HIV-positive pregnant women, and found that short course HAART was optimal for 6 or 12 months' breastfeeding. Badri et $\mathrm{al}^{14}$ demonstrated that HIV-infected adults cost $\$ 1,622$ per LYG, whereas AIDS patients cost $\$ 675$ per LYG.

Another three studies compared the roles of different types of HAART. Vijayaraghavan et $\mathrm{al}^{7}$ concluded that compared to the HAART based on developing-world guidelines, the ICER of HAART based on developed-world guidelines was $\$ 3,956$ per QALY and the net benefit was $\$ 39.4$ billion. McCabe et $\mathrm{al}^{18}$ demonstrated that both self-administered HAART and directly observed ART were associated with decreased costs and increased life expectancy compared to no HAART. Munakata et $\mathrm{al}^{19}$ built a model to compare two adherence scenarios: HAART in "ideal" (based on clinical trials) and in "typical" (based on observational studies in actual practice). With typical adherence, patients lost 1.2 QALYs that could be gained with ideal adherence.
The improvement of adherence to "ideal" levels exhibited cost-effectiveness at \$29,400 per QALY gained.

The last two studies compared HAART with other types of treatment. Marseille et $\mathrm{al}^{15}$ indicated that compared with cotrimoxazole + prophylaxis treatment, the HAART program averted 6,861 incremental DALYs. The net program cost was $\$ 4.09$ million. Ono et $\mathrm{al}^{23}$ demonstrated that HAART, vaccine treatment, and combined therapy averted $\$ 75, \$ 610$, and \$267 per DALY, respectively, compared to no intervention.

For the sensitivity analysis, most of the studies conducted an extensive one-way sensitivity analysis (Table 2), performed to illustrate the impact of individual parameter values on the results, as well as a two-way and probabilistic sensitivity analysis (Table 2), which demonstrated the impact of the results of all the combined uncertainty for all the parameter values.

\section{Discussion}

To our knowledge, this is the first review that summarizes economic evaluations related to HAART published over the course of the last 10 years. We identified 22 reports describing cost-effectiveness analyses of people living with HIV treated with HAART. The studies were grouped according to the similarity of the different intervention types and outcomes.

Cost-effectiveness analyses of comparisons between the specific HAART regimens adhered to the general guidelines of pharmacoeconomic evaluations. We did not undertake quality assessment of the reports, due to the limitation of length of article. In terms of results, an intervention may be considered cost-effective if the additional benefit provided by the treatment is considered "worth" the additional cost. ICERs per QALY tend to be the gold standard for economic evaluation. The advantage of using this parameter is the capacity to improve the comparability of studies and provide information that can therefore be used to aid policy makers regarding resource-allocation decisions. The WHO Commission on Macroeconomics and Health suggests that interventions may be considered quite cost-effective when the ICER is less than the per-capita gross domestic product, and can be accepted when the ICER is less than three times the per-capita gross domestic product. ${ }^{27}$ For example, some studies in this review indicated that DRV/r-based HAART was more cost-effective than other standard-of-care PI-based regimens among people living with HIV. The ICER was well below typical benchmark values and the ratios were robust, as demonstrated by one-way sensitivity and variability analyses or probabilistic sensitivity analyses. However, most of 
the studies that focused on specific HAART regimens only performed one-way or two-way sensitivity analysis, but not probability sensitivity analysis, which is the most effective method to check the stability of the model. Further studies are required to clarify this point.

In addition, it is difficult to compare the results of studies that analyze different kinds of HAART separately, since these are based on studies and trials that use different methodologies, including different study perspectives: payer, health system, or societal. The societal perspective is wider, since it considers the benefits and cost as a whole, especially cost. In theory, all costs, both direct and indirect, should be included in an economic evaluation from a social perspective. Moreover, in general, many analyses were actually based on comparisons with no intervention. The lack of head-to-head comparisons may reduce the value and reliability of results. Therefore, as this review demonstrates, more clinical trials or "typical" research based on different HAART regimens are required to provide more valuable results for health care decision making.

There are a number of limitations to this review. First, we included only studies published in the English language between January 2005 and December 2014, and earlier cost-effectiveness analyses, especially in the HAART era from 1996 to 2004, were omitted. Second, we did not evaluate the quality of these studies, because of the limitation of length of article. The effectiveness of HAART regimens is also influenced by patient adherence. Patient adherence may be reduced by the complexity of HAART or the onset of adverse events. Among the studies included in this review, only one study ${ }^{19}$ considered patient adherence in comparison between HAART regimens; therefore, further studies should be conducted to determine how patient adherence affects the cost-effectiveness of HAART. Finally, the review included a heterogeneous set of studies, such that it was not possible to consider pooling data for a meta-analysis. Therefore, this review is a comparative analysis, but not a quantitative analysis. Further studies should be conducted to determine the cost-effectiveness of HAART.

\section{Conclusion}

Our literature search revealed that many studies have been conducted to evaluate HAART from different perspectives. Most focused on comparisons between the specific HAART regimens, while others conducted analyses from the perspective of different people, such as IDUs versus non-IDUs and HIV-infected adults without AIDS versus those with AIDS, different types of regimens based on developed-world guidelines versus those based on developing-world guidelines, self-administered HAART versus directly observed HAART, and "ideal" versus "typical" studies. In terms of economic outcomes, we conclude that HAART is a better choice to deal with AIDS than other regimens or no intervention. ${ }^{9,11,15-18,20,22,23}$ Compared with HAART, tipranavir boosted with ritonavir ${ }^{5,12,26}$ seems to be a more cost-effective choice when compared with other specific regimens. No consistent conclusions were drawn from other comparisons. ${ }^{8,13}$ From the perspective of clinical biomarkers, ${ }^{21,24,25}$ treatment is more cost-effective if initiated early when CD4 counts $>350$ cells $/ \mathrm{mm}^{3}$.

In general, HAART is more cost-effective than other therapeutic regimens available to date. As combination antiretroviral regimens have become more potent and popular in both developed countries and developing countries, it is important to administer HAART at the appropriate time and among appropriate people. To identify the most suitable combination of HAART, further investigations are needed, especially analysis of head-to-head analyses based on "ideal" and "typical" trials of different combination of regimens.

\section{Author contributions}

All authors read and approved the final manuscript. WFT, WY, and WH contributions include selecting studies, collecting data, analyzing and presenting results, and writing and revising the manuscript. WH is responsible for the final content of the paper.

\section{Acknowledgment}

The authors were financially supported by the Project of Philosophy and Social Science Research in Colleges and Universities in Jiangsu Province (2014SJD085).

\section{Disclosure}

The authors report no conflicts of interest in this work.

\section{References}

1. World Health Organization. Global summary of the HIV/AIDS epidemic: 2013. 2014. Available from: http://www.who.int/hiv/data/ epi_core_dec2014.png?ua=1. Accessed February 25, 2015.

2. Montaner JG, Reiss P, Cooper D, et al. A randomized, double-blind trial comparing combinations of nevirapine, didanosine, and zidovudine for HIV-infected patients: the INCAS trial. Italy, The Netherlands, Canada and Australia Study. JAMA. 1998;279(12):930-937.

3. Cardoso SW, Torres TS, Santini-Oliveira M, Marins LM, Veloso VG, Grinsztejn B. Aging with HIV: a practical review. Braz J Infect Dis. 2013;17(4):464-479.

4. Montaner JS, Hogg R, Wood E, et al. The case for expanding access to highly active antiretroviral therapy to curb the growth of the HIV epidemic. Lancet. 2006;368(9534):531-536.

5. Moeremans K, Hemmett L, Hjelmgren J, et al. Cost effectiveness of darunavir/ritonavir 600/100 mg bid in treatment-experienced, lopinavirnaive, protease inhibitor-resistant, HIV-infected adults in Belgium, Italy, Sweden and the UK. Pharmacoeconomics. 2010;28(1):147-167. 
6. Long EF, Brandeau ML, Galvin CM, et al. Effectiveness and cost-effectiveness of strategies to expand antiretroviral therapy in St Petersburg, Russia. AIDS. 2006;20(17):2207-2215.

7. Vijayaraghavan A, Efrusy MB, Mazonson PD, Ebrahim O, Sanne IM, Santas CC. Cost-effectiveness of alternative strategies for initiating and monitoring highly active antiretroviral therapy in the developing world. J Acquir Immune Defic Syndr. 2007;46(1):91-100.

8. Hubben GA, Bos JM, Veltman-Starkenburg CA, et al. Cost-effectiveness of tipranavir versus comparator protease inhibitor regimens in HIV infected patients previously exposed to antiretroviral therapy in the Netherlands. Cost Eff Resour Alloc. 2007;5:15.

9. Johnston KM, Levy AR, Lima VD, et al. Expanding access to HAART: a cost-effective approach for treating and preventing HIV. AIDS. 2010; 24(12):1929-1935.

10. Binagwaho A, Pegurri E, Drobac PC, et al. Prevention of mother-tochild transmission of HIV: cost-effectiveness of antiretroviral regimens and feeding options in Rwanda. PLoS One. 2013;8(2):e54180.

11. Orlando S, Marazzi MC, Mancinelli S, et al. Cost-effectiveness of using HAART in prevention of mother-to-child transmission in the DREAMproject Malawi. J Acquir Immune Defic Syndr. 2010;55(5):631-634.

12. Brogan A, Mauskopf J, Talbird SE, Smets E. US cost effectiveness of darunavir/ritonavir $600 / 100 \mathrm{mg}$ bid in treatment-experienced, HIVinfected adults with evidence of protease inhibitor resistance included in the TITAN trial. Pharmacoeconomics. 2010;28 Suppl 1:129-146.

13. Simpson KN, Roberts G, Hicks CB, Finnern HW. Cost-effectiveness of tipranavir in treatment-experienced HIV patients in the United States. HIV Clin Trials. 2008;9(4):225-237.

14. Badri M, Maartens G, Mandalia S, et al. Cost-effectiveness of highly active antiretroviral therapy in South Africa. PLoS Med. 2006;3(1):e4.

15. Marseille E, Kahn JG, Pitter C, et al. The cost effectiveness of homebased provision of antiretroviral therapy in rural Uganda. Appl Health Econ Health Policy. 2009;7(4):229-243.

16. Rizzardini G, Bonfanti P, Carenzi L, et al. Cost-effectiveness analysis of HIV treatment in the clinical practice of a public hospital in northern Italy. Ther Clin Risk Manag. 2012;8:377-384
17. Colombo GL, Di Matteo S, Antinori A, Medaglia M, Murachelli S, Rizzardini G. Economic evaluation of initial antiretroviral therapy for HIV-infected patients: an update of Italian guidelines. Clinicoecon Outcomes Res. 2013;5:489-496.

18. McCabe CJ, Goldie SJ, Fisman DN. The cost-effectiveness of directly observed highly-active antiretroviral therapy in the third trimester in HIV-infected pregnant women. PLoS One. 2010;5(4):e10154.

19. Munakata J, Benner JS, Becker S, Dezii CM, Hazard EH, Tierce JC. Clinical and economic outcomes of nonadherence to highly active antiretroviral therapy in patients with human immunodeficiency virus. Med Care. 2006;44(10):893-899.

20. Colombo GL, Colangeli V, Di Biagio A, Di Matteo S, Viscoli C, Viale P. Cost-effectiveness analysis of initial HIV treatment under Italian guidelines. Clinicoecon Outcomes Res. 2011;3:197-205.

21. Granich R, Kahn JG, Bennett R, et al. Expanding ART for treatment and prevention of HIV in South Africa: estimated cost and cost-effectiveness 2011-2050. PLoS One. 2012;7(2):e30216.

22. Fang CT, Chang YY, Hsu HM, et al. Cost-effectiveness of highly active antiretroviral therapy for HIV infection in Taiwan. J Formos Med Assoc. 2007;106(8):631-640.

23. Ono S, Kurotaki T, Nakasone T, et al. Cost-effectiveness analysis of antiretroviral drug treatment and HIV-1 vaccination in Thailand. Jpn J Infect Dis. 2006;59(3):168-173.

24. Badri M, Cleary S, Maartens G, et al. When to initiate highly active antiretroviral therapy in sub-Saharan Africa? A South African costeffectiveness study. Antivir Ther. 2006;11(1):63-72.

25. Mauskopf J, Kitahata M, KaufT, Richter A, Tolson J. HIV antiretroviral treatment: early versus later. JAcquir Immune Defic Syndr. 2005;39(5): $562-569$.

26. Mauskopf J, Brogan A, Martin S, Smets E. Cost effectiveness of darunavir/ritonavir in highly treatment-experienced, HIV-1-infected adults in the USA. Pharmacoeconomics. 2010;28 Suppl 1:83-105.

27. Harris M, Nosyk B, Harrigan R, Lima VD, Cohen C, Montaner J. Costeffectiveness of antiretroviral therapy for multidrug-resistant HIV: past, present, and future. AIDS Res Treat. 2012;2012:595762.
ClinicoEconomics and Outcomes Research

\section{Publish your work in this journal}

ClinicoEconomics \& Outcomes Research is an international, peerreviewed open-access journal focusing on Health Technology Assessment, Pharmacoeconomics and Outcomes Research in the areas of diagnosis, medical devices, and clinical, surgical and pharmacological intervention. The economic impact of health policy and health systems

\section{Dovepress}

organization also constitute important areas of coverage. The manuscript management system is completely online and includes a very quick and fair peer-review system, which is all easy to use. Visit http://www.dovepress.com/testimonials.php to read real quotes from published authors. 